\title{
Dick Tracy, o filme high concept e o cinema brasileiro
}

\author{
Fermando Mascarello
}

\begin{abstract}
Resumo
Dick Tracy (Warren Beatty, 1990) é um exemplo bastante consistente do que o meio cinematográfico norte-americano tem denominado "high concept movie". Caracterizados pelo excesso estilistico e pela fragilização da narrativa, e considerados a manifestação central de um suposto cinema hollywoodiano pós-clássico ("post-classical Hollywood cinema"), estes filmes são o produto de uma inédita determinação da forma por aspectos mercadológicos e industriais. O trabalho de estilização realizado sob a moldura de uma narrativa simples, porém modular - verifica-se uma autonomização de seções do filme que excedem, individualmente, aos requisitos da narrativa - oferece os icones, imagens e descrições telegráficas da trama utilizados como ganchos de marketing. Tomando como objeto analítico o filme de Beatty, o artigo procura apontar as implicações deste formato textual e mercadológico do filme high concept sobre os modos de espectatorialidade cinematográfica contemporâneos, pensando o seu entendimento como contribuição para o permanente esforço do cinema brasileiro com vistas à conquista de mercado e repercussão cultural.
\end{abstract}

Palavras-chave: cinema, high concept, pós-clássico, Nova Hollywood, espectador

\section{Abstract}

Dick Tracy (Warren Bealty, 1990) is a convincing example of what the American film milieu has called "high concept movie". Characterized by stylistic excess and narrative disruption, and considered as the fundamental manifestation of an alleged "post-classical Hollywood cinema", these movies are the result of a previously unseen overdetermination of form by marketing and industrial features. The stylizalion produced within the framework of a simple but modular narrative - an autonomization occurs of sections of the film which exceed, individually, the demands of narrative - provides the icons, images and brief plot summaries utilized as marketing hooks. Taking Bealty's film as its analytic object, this paper aims at pointing out the implications of such a textual and marketing format of the high concept movie on contemporary modes of cinemalic spectatorship, viewing their comprehension as a contribution to the permanem efforts of Brazilian cinema towards wiming more significant market shares and cultural significance.

Key words: mask-images, digital inclusion, philanthropy industr'

\footnotetext{
- Doutor em Cinema pela Escola de Comunicação e Artes da Universidade de São Paulo (ECA/USP). coordenador do curso de Realização Audiovisual da Universidade do Vale do Rio dos Sinos (UNISINOS). membro do Conselho Executivo da SOCINE (Sociedade Brasileira de Estudos de Cinema), editor das revistas Teorema - Critica de Cinema (Porto Alegre, RS) e AV/Audiovisual (São Leopoldo, RS). pesquisador da UNISINOS na área de cinema e audiovisual.
} 
A escolha de um filme como Dick Tracy (Warren Beatty, 1990) como objeto de análise pode parecer intrigante. Em recaindo o foco da investigação sobre um universo fílmico tão rico como a década de 1990 - como acontece ser o caso do presente artigo -, porque não dedicar-se a filmes como os de David Cronenberg, Atom Egoyan, David Lynch, Quentin Tarantino, etc.? Ou por que, no terreno do blockbuster, não eleger uma realização esteticamente mais bem-sucedida, como Batman, O Retorno (Batman Returns, Tim Burton, 1992), ou comercialmente mais efetiva, como Titanic (James Cameron, 1997)?

De costume, é o amor ou devoção ao filme ou cineasta que mobilizam o analista. Nesse texto, abro mão desta prerrogativa para analisar Dick Tracy. O que prevalece, aqui, é o fascínio não pelo filme, mas pelo conceitual estético e teórico que este pode mobilizar. Uso o filme como pretexto para examinar algumas noções da história contemporânea de Hollywood que não têm sido apreciadas a contento no meio cinematográfico brasileiro: Nova Hollywood (New Hollywood), cinema pós-clássico (ou neoclássico) e, sobretudo, filme high concept. ${ }^{1}$ Vinculam-se, todas, a uma generalizada tendência de privilégio ao espetáculo em detrimento da narração, em íntima associação com a metodologia agressiva de marketing e o direcionamento do produto aos mercados secundários de exibição e consumo.

Dick Tracy é um filme que clama por estas noções para a sua análise. Como espetáculo visual, é arrebatador. As imagens pós-expressionistas dos quadrinhos de Chester Gould são vertidas cinematograficamente com maestria por Warren Beatty e equipe, através de um impecável desenho de produção (esquema de cores, maquiagem, cenografia) e de uma utilização inteligente da câmera (movimentos contidos) e da montagem (cortes abruptos). Além disso, os atributos mercadológicos do filme (a marca visual inconfundível, a presença dos atores Al Pacino, Dustin Hoffman e Madonna, a remissão aos quadrinhos, a dupla trilha assinada por Danny Elfman e Madonna) são ativados por uma onipresente campanha de marketing e pelo ofertamento de produtos relacionados, os chamados "negócios conexos", enredando o espectador em uma teia semiótica que extravasa o mero texto fílmico.

Mas o resultado estético final é controverso. Narrativamente, o trabalho dramatúrgico e de caracterização das personagens é sacrificado. E renuncia-se a uma exploração criativa das possibilidades temáticas e genéricas do filme. O resultado disso é a incapacidade para propor figuras esteticamente significativas na convergência entre imagem e narrativa. Enfim, observa-se a aposta no espetáculo às custas da narração, sintetizável no par excesso visual / desnarrativização.

Esta nova maneira de (des)equilibrar espetáculo e narrativa (que pode manifestar-se de formas diversas das de Dick Tracy, como, por exemplo, no filme de ação-aventura e no melodrama) é francamente determinada pelo econômico e o industrial, constituindo, sem dúvida, peça basilar do conjunto 
da produção hollywoodiana contemporânea, pós-Tubarão (Jaws. Steven Spielberg, 1975) e Guerra nas Estrelas (Star Wars, George Lucas, 1977). Dick Tracy, sob este ponto de vista, é um típico representante desta nova estética. Mas, mais que isso, a meu ver o filme é particularmente emblemático do curso histórico assumido por Hollywood na década de 1990. de virada no sentido da diluição estética desta Nova Hollywood (evidentemente, para boa parte dos críticos - simpáticos ou não à "velha" Hollywood -, esta já em si é caracterizada pelo esvaziamento). Aqui, a comparação com Batman (o primeiro da série, de 1989) é muito didática: de enormes semelhanças com o filme de Tim Burton (a adapatação a partir dos quadrinhos, a estilização do cenário urbano e a ênfase sobre o visual, a tematização do grotesco, o formato duplo da trilha sonora de Danny Elfman e Prince, o marketing de extrema saturação, etc.), o filme de Beatty é porém flagrantemente menos denso, dramática e psicologicamente. (A inadequação da trilha de Elfman, por exemplo, é gritante, quase um pastiche frente ao seu trabalho de ruptura em Batman.)

A mobilização de conceitos como Nova Hollywood, cinema hollywoodiano pós-clássico e filme high concept é estratégica para a compreensão deste desequilíbrio entre imagem e narrativa em Dick Tracy. (percebido como tal justamente em sua confrontação com o "equilíbrio" do filme clássico). A partir do princípio da década de 1970, a expressão $\mathrm{New}$ Hollywood começa a ser aplicada ao chamado American Art Film de Monte Hellman, Robert Altman, Arthur Penn, Francis Ford Coppola, Martin Scorsese e outros, de final dos anos 1960 e início dos 1970. Porém, em uma curiosa transformação, o termo passa a designar, posteriormente, exatamente a produção mainstream que não apenas decreta o encerramento do ciclo do American Art Film, como garante a reestabilização econômica de Hollywood: o blockbuster à Lucas e Spielberg, que reelabora o filme $\mathrm{B}$ da década de $50 \mathrm{e}$ inaugura as práticas de marketing de saturação e dos negócios conexos. ${ }^{2}$ É interessante, porém, observar que tanto uma formação como a outra se afastam, narrativamente, do cinema hollywoodiano clássico: se o American Art Film abandona a cadeia narrativa de causa e efeito típica do filme clássico, com seus protagonistas bem-definidos em busca de objelivos claros ${ }^{3}$, o novo blockbuster, embora configurando um retorno à fluência ("transitividade") narrativa, promove o enfraquecimento da personagem e da dramaturgia. paralelamente à valorização dos aspectos superficiais da imagem, através dos efeitos especiais e da estilização.

Esta "desnarrativização" (especialmente a do novo blockbuster) é um dos traços centrais do suposto pós-classicismo hollywoodiano. O "pósclássico" é um dos conceitos mais polêmicos sobre a Hollywood contemporânea, servindo para designar tanto um período (aquele que sucede ao clássico) como um estilo (definido por sua intensa determinação pelo econômico, inédita sob os pontos de vista qualitativo e quantitativo). $\mathrm{O}$ 
termo rival, "neoclássico", dele se distingue por sua sugestão de um retorno a um estado de coisas precedente, o clássico, e, logo, por sua comprensão do American Art Film como tão-somente um período de transição necessário, histórica e esteticamente, à reestruturação da indústria hollywoodiana. ${ }^{4}$ Ambos os conceitos partilham, no entanto, o diagnóstico da erosão do narrativo, causada por determinantes industriais e mercadológicos. Consistem estes na conglomeração da indústria midiática transnacional e na decorrente integração horizontal de estúdios e filmes em uma extensa cadeia de produção e consumo de bens de entretenimento.

$\mathrm{O}$ conceito mais elaborado proposto até o momento com vistas a examinar esta determinação da forma pelo econômico na Hollywood contemporânea é o de filme "high concept". A noção, corrente na indústria cinematográfica americana desde o final dos anos 1960, é teoricamente elaborada pelo americano Justin Wyatt em seu livro High Concept: Movies and Marketing in Hollywood, de 1994. ${ }^{5}$ Conforme o autor, a incorporação dos estúdios a grandes conglomerados multimidiáticos, a partir dos anos 1970, resulta na produção de filmes cada vez mais voltados aos mercados secundários (ou "ancilares") de exibição e consumo - TV, cabo, vídeo, merchandising, negócios conexos, etc. - num processo tecnicamente designado como de "sinergia" entre os vários ramos da indústria de entretenimento (através do qual os diferentes meios ou mercados se reforçam e retroalimentam em termos de marketing e operam como anteparos 72 econômicos mútuos para o caso de fracassos pontuais do produto). Estes vários mercados são conquistados por meio de campanhas de marketing que passam a absorver parcelas progressivamente mais significativas dos orçamentos finais dos filmes.

Neste cenário, o filme high concept apresenta como atributo central a sua forma motivada pela necessidade de provimento dos ícones, imagens e descrições telegráficas de trama utilizados como ganchos de marketing. Para tanto, possui uma narrativa simples e fragmentada em módulos, caracterizados, estes, por um trabalho de estilização que "excede" os requisitos da narrativa, promovendo a sua autonomização no interior da estrutura da obra. Graças à sua adaptação aos imperativos econômicos, estes filmes tendem a ser os mais lucrativos em Hollywood. (Vale observar que nem todos os chamados "filmes de altíssimo orçamento" - os mais caros dentre os blockbusters seguem a fórmula do high concept, o contrário sendo também verdadeiro: um filme high concept não é obrigatoriamente um blockbuster).

Para alguns, pensar a Hollywood contemporânea com base em conceitual americano sem origens claras no pensamento acadêmico de esquerda pode parecer adesista e politicamente suspeito. Mas se a função precípua da academia é a reflexão, a atual omissão da universidade brasileira com relação ao tema concorre para a repetição em clichês e impressionismos 
(para não dizer "coitadismos") dentro e fora de seus domínios. Além disso, conceitos como Nova Hollywood, pós-clássico e high concept não possuem valência política definida, assumindo contomos mais ou menos críticos de seu objeto conforme o autor ou corrente que os ativam. A meu ver, o cinema brasileiro só teria a ganhar com uma compreensão mais científica (teórica) do atual cinema hollywoodiano, da qual poderia se valer na luta pela ampliação de seus espaços de mercado-e, aqui, ingressamos no terreno do político. É com esse duplo intuito - teórico e político, portanto - que ensaio um exame de Dick Tracy como filme high concept, à guisa de exemplo das possibilidades críticas e analíticas do conceitual sobre a Hollywood contemporânea.

Do ponto de vista do cinema brasileiro, a análise das relações entre estética e economia - das transformações do equilíbrio imagem/narrativa determinadas pela estrutura industrial fundada sobre o marketing e a sinergia - pode contribuir sobretudo com uma melhor compreensão do comportamento do público. A relação entre espectador e filmes é modificada. em primeiro lugar, pela nova organização textual das próprias obras, implicando vínculos mais superficiais com a narrativa e as personagens. E, em segundo lugar. pelo extravasamento do texto fílmico em uma profusão de intertextos em seu entorno (campanhas promocionais, produtos conexos como trilhas, acessórios, jogos, novelizações), os quais, contribuindo para a ruptura da unidade diegética do filme, estimulam o seu repetido consumo através dos vários mercados ancilares.

A seguir, portanto, exploro os aspectos high concept de Dick Tracy, buscando perceber suas implicações sobre o (des)equilíbrio entre narrativa e estilização no filme e verificar as suas consequiências sobre a espectatorialidade.

Como principal característica do filme high concept, Wyatt aponta a sua qualidade "excessiva", conforme a oposição entre estilo e excesso proposta pela neoformalista Kristin Thompson." Para esta autora, o estilo é constituído por técnicas que, tendo em vista a sua repetição, tornam-se estruturantes da obra, sendo o excesso, ao contrário, causado pelas técnicas que não constroem padrões específicos no texto fílmico. Se o primeiro opera no sentido da compreensão do filme pelo espectador, o segundo instaura uma lacuna entre espectador e narrativa. ${ }^{7} \mathrm{O}$ (paradoxal) "estilo excessivo" do high concept, segundo Wyatt, é o produto de pressões econômicas relacionadas à necessidade de disponibilização de imagens para a promoção do filme e o lançamento de produtos conexos. Tal processo é articulado mediante a utilização da estética publicitária e sua costumeira transformação de imagens cotidianas em visões dramáticas, que induzem à apreciação da composição formal da obra.

Cinco são os elementos essenciais através dos quais se manifesta o estilo high concept: a aparência visual, a performance dos stars, a música, a 
personagem e o gênero. ${ }^{8} \mathrm{Na}$ descrição de Wyatt, os filmes high concept individuais optam normalmente por apenas alguns dentre estes elementos, dependendo da forma como o seu estilo particular se integra às ações de marketing. O primeiro, a visualidade, caracteriza-se pela iluminação baseada no contraluz, o esquema de cores mínimo, próximo do preto-e-branco, e uma cenografia high tech derivada do design industrial contemporâneo. Tem como funções a criação de uma identidade consistente para o filme/produto e o oferecimento de imagens superficialmente atraentes.

Embora a aparência visual seja um dos aspectos mais salientes em Dick Tracy, é curioso que, conforme afirma o próprio Wyatt, ${ }^{9}$ esta não chega a configurar uma visualidade high concept, em que pese a indicação, pelo autor, do filme de Beatty como um exemplo bastante representativo do estilo (como veremos, a obra exibe todos os seus outros traços estilísticos definidores). E, de fato, o desenho de produção do filme não replica nenhum dos aspectos apontados por Wyatt como característicos do "visual" high concept. Porém, a meu ver, é possível constatar em sua visualidade pelo menos três predicados do estilo high concept: o caráter excessivo frente aos requisitos da trama, o convite ao prazer estético de superfície, liberto de funções propriamente narrativas, e seu extensivo aproveitamento como marca visual distintiva da obra.

A bem da verdade, creio que a imagem em Dick Tracy talvez não seja excessiva no sentido parcial com que Wyatt se apropria do conceito de 74 Thompson, o de "técnicas que não formam padrões específicos na obra". Afinal de contas, o desenho de produção do filme constrói padrões consistentes de escolhas fotográficas, cenográficas, de figurino, composição, etc. No entanto, um exame mais detido da noção de excesso em Thompson nos revelará que o interesse da autora recai, não na simples fuga a padrões estruturais, mas em uma compreensão muito mais ampla dos aspectos do texto "não contidos por suas forças unificadoras". ${ }^{10}$ (A autora revisa as origens históricas desta empreitada teórica, identificando nas obras dos formalistas russos e de Barthes momentos-chave de seu desenvolvimento e atribuindo a proposição inicial do termo a Stephen Heath. ${ }^{11}$ ) Sua formulação do excesso indaga sobre o modo como "cada elemento de estilo pode a um só tempo contribuir para a narrativa mas também para dela desviar a nossa percepção". O excesso, no entendimento de Thompson, é "contranarrativo" e "contrário à unidade", produto de uma "defasagem" com relação à sua motivação composicional na obra. ${ }^{12}$ É neste sentido que me parece ser pertinente a aplicação do termo ao descolamento entre imagem e narrativa no filme de Beatty. ${ }^{13}$

Um segundo elemento do estilo high concept compreende a performance dos astros hollywoodianos. De acordo com Wyatt, esta visa à maximização de sua condição de stars, e define-se pela interpretação 
ostentatória, fundada no gesto, em oposição ao trabalho mais naturalista do restante do elenco. A título de exemplo, o autor cita a atuação performática de Jack Nicholson em Batman, e observa como é flagrante a precedência da performance sobre o desenrolar da narrativa. ${ }^{14}$ Além de excessiva, a atuação dos stars é ainda conformadora de módulos autônomos no interior do filme. Em meu ponto de vista, Dick Tracy certamente se utiliza deste expediente. e um paralelo interessante pode ser estabelecido com o filme de Burton: se neste a interpretação de Nicholson destaca-se frente à contenção de Michael Keaton, no de Beatty o desempenho performático de Al Pacino e Dustin Hoffman (como a dupla de vilōes Big Boy e Mumbles) contrasta com o trabalho esquemático de Warren Beatty e Glenne Hedly (como o casal de protagonistas Tracy e Tess).

Já a presença de Madonna (como a showgirl Breathless Mahoney) é vinculada, naturalmente, à sua condição de estrela do universo pop musical. Embora não sendo representável visualmente, a música é o terceiro elemento de expressão da estilística high concept - segundo Wyatt, talvez o mais significativo em termos do marketing e dos negócios conexos, devido à crescente juvenilização do público no circuito primário de exibição. O autor recorre outra vez a Thompson, a qual assinala o caráter especialmente disruptivo da música para a unidade do filme, tendo em vista a sua capacidade para concentrar as atenções sobre as próprias qualidades formais, independentemente de sua função imediata com relação à imagem. ${ }^{15}$ Conforme Wyatt, os filmes high concept (o mais das vezes não pertencentes ao gênero do musical) contêm "explosões musicais" momentâneas que, ao contrário do que sucede nas obras daquele gênero, efetivamente perturbam o seu equilíbrio estrutural. Em sua combinação com a imagem (geralmente associada à adoção da estética do videoclipe, de forte fragmentação da unidade espacial e/ou temporal), estas irrupções compõem módulos estanques (extraíveis para a promoção do filme e do álbum com a trilha sonora) cujo excesso opera contra a seqüiencia da narrativa.

Se analisarmos Dick Tracy, é patente a qualidade modular das aparições musicais de Madonna/Mahoney, embora a linguagem do videoclipe não se faça presente. Ironicamente, parece até mesmo se manifestar uma espécie de resistência do sistema textual da obra contra a modularização, nos insistentes cortes dos números musicais antes de sua resolução dramática, constituindo como que um "sintoma reativo" frente à enfermidade que acomete a narração. Além de alterar o balanço estrutural do texto fílmico, afïrma Wyatt. a música é talvez o grande veículo para outro importante atributo do high concept: a destruição da unidade diegética do filme por meio da reconfiguração da narrativa nos materiais promocionais e negócios conexos. $\mathrm{O}$ autor se vale de formulações da teórica Barbara Klinger sobre o tema, em que esta analisa como as campanhas de marketing perseguem a multiplicação dos possíveis 
sentidos da narrativa, com vistas ao incremento das possibilidades de comunicação com o público. É criada uma zona intertextual com base no "assalto" ao texto fílmico em busca de figuras passíveis de acentuação ou extensão no processo de apropriação da obra pela audiência. ${ }^{16}$ Como uma das manifestações mais significativas do fenômeno, Wyatt aponta a interação entre cantor e protagonista nos vídeos promocionais dos filmes. Um dos exemplos citados é o clipe de Danger Zone, tema de Top Gun - Ases Indomáveis, no qual a interpretação de Kenny Loggins, deitado na cama e assumindo o papel de duplo da personagem de Tom Cruise, "comenta" as sequiências aéreas parecendo sugerir que a verdadeira "zona de perigo" está não no ar, mas em terra. No outro exemplo, a figura do exterminador vivido por Arnold Schwarzenegger invade um show dos Guns N' Roses no clipe para a canção do segundo filme da série, o que demarca um claro transbordamento do mundo diegético original do filme. ${ }^{17}$

Em Dick Tracy, segundo Wyatt, o processo de ruptura da unidade diegética da obra é materializado no álbum de Madonna com faixas não pertencentes, mas somente inspiradas no filme. Outra vez, é nítida a proximidade entre Batman e Dick Tracy. Cada filme conta com dois discos, o primeiro basicamente trazendo a trilha instrumental (de Danny Elfman) e o segundo de autoria de um artista associado à obra (Prince e Madonna). Apenas três canções do disco de Madonna estão incluídas em Dick Tracy, e, das demais, enquanto algumas se relacionam com personagens ou trechos do filme, outras não mantêm com este qualquer vínculo. Além disso, conforme sugere Wyatt, em algumas das faixas a cantora imita os estilos de Carmen Miranda ou Betty Boop, de todo incongruentes com a temática fílmica ou com a sua personagem, Mahoney. Isso produz um desvirtuamento da narrativa, exposta a um conjunto de personagens baseadas no conceito bastante amplo de desejo feminino. A sabotagem da narrativa nos álbuns de Prince e Madonna também ocorre pelo uso do sampling. Em uma das faixas, o autor observa que a cantora/atriz interage com o mundo diegético respondendo a chamados por Tracy sampleados do filme, em meio à reprodução incansável de amostras da palavra "dick" (cacete). ${ }^{18}$ Segundo Wyatt, a enfatização destes elementos extraídos da obra produz a sua sobredeterminação no tecido textual, tornando-os excessivos frente à narrativa.

O quarto e o quinto elementos estilísticos do high concept identificados por Wyatt são seu recurso à tipologização das personagens $\mathrm{e}$ às fórmulas genéricas hollywoodianas. A apresentação de personagens como tipos definidos por um número mínimo de atributos, com destaque para a aparência física, tem sido um procedimento habitual do cinema clássico, mas para Wyatt é exacerbada no filme high concept. O mesmo pode-se dizer das convenções genéricas, utilizadas crescentemente como meios econômicos 
de transmissão de informação. O efeito combinado dos dois elementos é a drástica redução da necessidade de exposição dos desejos e motivações das personagens, fazendo-as unidimensionais.

Este me parece ser em grande medida o caso de Dick Tracy. Basta ver que os relacionamentos sexuais no filme - Tracy e Tess, Tracy e Mahoney e Big Boy e Mahoney - reproduzem convençōes fortemente estereotipadas do policial (o detetive casado com o trabalho), do noir (o detetive durão sobrepujando a femme fatale) e do filme de gângster (o vilão e sua mulher-objeto). Aparentemente, em associação com a tipologização física (principalmente das personagens de Beatty e Madonna), isso é o suficiente para as escassas necessidades narrativas da obra, trazendo como resultado a composição de personagens rígidas e previsíveis.

A análise dos elementos high concept de Dick Tracy encaminha uma compreensão global do aspecto mais saliente do filme, o desequilíbrio entre grandiosidade do espetáculo e indigência da narrativa. São particularmente úteis, neste sentido, os conceitos de excesso, modularidade e superficialidade. A imagem excede aos requisitos da narrativa, ao que se agrega a interpretação também excessiva de Al Pacino e Dustin Hoffman. Por sua vez, a atuação over dos stars reforça o caráter modular do tex to fílmico determinado pelas aparições musicais de Madonna, resultando na obstrução do fluxo da narração. Em paralelo, $o$ apelo visual tende ao esgotamento nos aspectos superficiais da imagem, em um processo que se replica no superficialismo da trama e das personagens, fundados sobre os clichês genéricos e a tipologização física. As consequiências da conjugação entre excesso e surerfície são óbvias: a despotencialização da estrutura dramática de Dick Tracy e a incapacidade de aprofundamento dos temas propostos (a relação do par lei/crime com o grotesco, o embate à noir entre o masculino e o feminino, a representação visual do urbano como espaço simbólico dessa tematização, etc.). Ou, em outras palavras: a desvalorização da narrativa frente ao excesso e superficialidade do espetáculo.

Quanto às relações do filme high concept com o espectador, são peculiares tanto em razão da estrutura textual da própria obra como pela intensificação semiológica do espaço intertextual em seu entorno. Para Wyatt, o texto fílmico em si deflagra uma fruição distanciada, na qual o espectador interage, sobretudo, com as qualidades superficiais do filme. Em pouco semelhante ao brechtiano, obviamente, este distanciamento é observável, segundo o autor, em uma série de atitudes espectatoriais recomendadas pelo texto, de que são exemplo a entrega à contemplação da imagem pela imagem, a identificação mais débil com as personagens e o reconhecimento da autonomia textual dos módulos de espetáculo - associadas, sempre, à erosão do interesse pelo sistema narrativo do filme (e todas elas induzidas por Dick Tracy). ${ }^{19} \mathrm{Já}$ o campo intertextual em torno à obra, amplificado pelo incremento 
contemporâneo das campanhas de marketing, adquire grande relevância por sua tendência à promoção da ruptura da unidade diegética do texto fílmico. De acordo com Wyatt, isso convida a uma fruição recorrente (repeat viewing) dos filmes, com prazeres baseados no jogo entre o familiar (o texto original) $e$ o diferente (o texto reconfigurado). ${ }^{20}$

No processo em que se insere o high concept, esta revisitação à obra, segundo o autor, é crucial para o estabelecimento dos efeitos sinérgicos entre os diversos ramos da indústria do entretenimento. Deste modo, o consumo de um filme como Dick Tracy, por exemplo, apenas se inicia pelo cinema, para logo percorrer a extensa cadeia dos mercados ancilares de exibição (vídeo, cabo, TV aberta) e de venda de produtos conexos (reloginhos de Tracy, trilha de Madonna, história em quadrinhos original, etc.).

Do ponto de vista do cinema brasileiro, seria interessante perceber que, sendo o marketing um dos pilares centrais da reconfiguração estética e industrial de Hollywood a partir de meados dos anos 70, é fundamental compreeender suas profundas implicações sobre a forma fílmica e a espectatorialidade. Como vimos, estas incluem: (1) a criação do filme tendo em vista a sua marquetabilidade; (2) a amplificação do campo intertextual em torno ao filme como resultado da ação semiológica de materiais promocionais e produtos conexos, envolvendo o transbordamento do texto fílmico e a própria ruptura de sua unidade diegética; e (3) a modificação das práticas espectatoriais, estimulada pela reestruturação do texto fílmico (a "fruição distanciada") e pela intensificação de seu entorno intertextual (a "fruição recorrente").

Sugerir a simples incorporação, pelo cinema brasileiro, de estratégias textuais como as materializadas no filme high concept, seria ingênuo e pouco realista. Desenvolvidas no seio da indústria do entretenimento americana, ajustam-se à sua organização estético-industrial específica e ao seu imenso poderio econômico (para não mencionar que a própria Hollywood reconhece os sinais de seu esgotamento estético ao longo da última década). A meu ver, a grande lição do high concept é a possibilidade de pensar conjuntamente texto filmico e estratégias de marketing - estética e economia - no cinema nacional, seja este o clássico (ou pós-clássico) ou o de arte. Isso implica, com certeza, o desafio a dois pressupostos dos céticos: o binômio autonomia textual/gênio artístico e as visões manipulatórias, frankfurtianas do marketing. Além de supor, é claro, a crença na necessidade de uma indústria cinematográfica nacional sólida e pluralista. Se a opção (do cinema de arte, em particular) for pela comunicação com o público, é prioritário identificar, como objetivo de fundo do marketing, a criação de uma zona intertextual cada vez mais densa ao redor do texto fílmico (materiais promocionais, negócios conexos, entrevistas, textos críticos), com funções de mediação entre a obra e sua audiência. E, acima de tudo, reconhecer a enorme dependência deste espaço intertextual para com a organização estética do próprio filme. 
Em uma perspectiva mais ampla, uma questão ao menos deveria ser formulada: de que maneira a compreensão das atuais estratégias do adversário hollywoodiano poderia contribuir para o esforço do cinema brasileiro de conquista de mercado e repercussão cultural? Com esta análise, espero ter colaborado para um entendimento mais efetivo das relações entre economia, estética e espectatorialidade na Hollywood contemporânea.

\section{Notas}

' Para Jacques Aumont e Michel Marie. nas análises em que é explícita a motivação teórica são identificáveis três tipos de relações entre análise fílmica e teoria do cinema: invenção (a análise como instância de elaboração conceitual), verificação (a aplicação do modelo teórico de modo a examinar sua validade ou constatar imprecisões) e demonstração ou promoção (o texto analítico como instrumento de divulgação de conceitos) (em Análisis del Film (Barcelona: Paidós. 1993. 2 ed.. p. 279-81)). A presente análise de Dick Tracy contém elementos de cada una destas três modalidades. sendo meu objetivo principal a demonstração da necessidade de uma maior formulação teórica, no país, sobre o cinema hollywoodiano contemporâneo.

'Sobre a transformação do sentido do termo, ver Murray Smith. "Theses on the Philosophy of Hollywood History". in Steve Neale e Murray Smith (Orgs.). Contemporary Hollywood Cinema (Londres: Routledge, 1998), p. 11; ou, ainda em maior detalhe, Peter Kramer, "Post-classical Hollywood". in John Hill e Pamela Church Gibson (Orgs.), American Cinema and Hollywood (Oxford: Oxford University Press, 2000), particularmente p. 69-79. Em seu sentido original. a Nova Hollywood foi apreciada por Thomas Elsaesser em "The Pathos of Failure. American Films in the 1970s: Notes on the Unmotivated Hero". Monogram 6: e por Steve Neale em "New Hollywood Cinema". Screen 17.2. O corpus de diretores e filmes abrangidos nesta acepção do termo foi objeto de estudo ainda em Michael Pye e Lynda Myles. The Movie Brats: How the Film Generation Took over Hollywood (Nova lorque: Holt, Rinehart \& Winston, 1979): e em Robert Phillip Kolker. A Cinema of Loneliness: Penn, Kubrick, Coppola, Scorsese. Altman (Nova Iorque: Oxfod University Press. 1980). No sentido posterior do termo, a Nova Hollywood foi investigada por Thomas Schatz em "The New Hollywood", in Jim Collins, Hilary Radner e Ava Preacher Collins (Orgs.). Film Theory Goes to the Movies (Nova Iorque: Routledge. 1993).

"Reporto-me aqui à caracterização teórica do cinema clássico empreendida sistematicamente por David Bordwell em textos como "Classical Hollywood Cinema: Narrational Principles and Procedures", in Philip Rosen (Org.). Narrative. Apparatus. Ideology (Nova Iorque: Columbia University Press. 1986): Narration in the Fiction Film (Madison, Wisconsin: University of Wisconsin Press. 1985); e no hoje canônico livro em co-autoria com Janet Staiger c Kristin Thompson. Classical Hollywood Clnema: Film Style and Mode of Production to 1960 (Nova Iorque: Columbia University Press. 1985).

`Sobre o pós-clássico, ver, por exemplo. Smith. op. cit. Nota 2: Richard Maltby. "Nobody Knows Everything: Post-classical Historiographies and Consolidated Entertainment", in Neale e Smith, op. cit. Nota 2: e Kramer, op. cit. Nota 2. Sobre o neoclássico. ver especialmente Schatz. op. cit. Nota 2. 
${ }^{5}$ Austin: University of Texas Press.

${ }^{6}$ Idem, p. 27-28.

${ }^{7}$ Thompson, "The Concept of Cinematic Excess", in Philip Rosen (Org.), Narrative, Apparatus, Ideology (Nova Iorque: Columbia University Press, 1986), p. 132.

${ }^{8} \mathrm{Na}$ descrição dos elementos estilísticos do high concept que segue, gloso, em sua maior parte, a formulação de Wyatt no capítulo 2 de sua obra (p. 23-64). Quanto ao exame dos aspectos high concept em Dick Tracy, algumas das observações são suas, mas a maior parte minhas, segundo se depreende do texto e das notas.

${ }^{9}$ Wyatt, op. cit. Nota 5 , p. 30 .

10 Thompson, op. cit. Nota 6, p. 130.

${ }^{11} \mathrm{O}$ texto de Heath especificamente citado por Thompson é "Film and System: Terms of Analysis, Pt. I", Screen 16, 1 (Primavera 1975).

${ }^{12}$ Thompson, op. cit. Nota 6, p. 134.

${ }^{13}$ Tanto Heath quanto Thompson empregam o conceito como ferramenta analítica do cinema hollywoodiano clássico em termos de sua contenção do excesso em favor da narrativa (em contraste com o que sucede nas várias formas de contracinema ou cinema de arte). Embora Wyatt não explicite o fato em seu livro, sua evidente intenção ao utilizar-se do conceito é certamente a de produzir um efeito de paradoxo ao aplicálo à análise da manifestação (e não da contenção) do excesso no próprio cinema hollywoodiano. O uso paradoxal do conceito só faz evidenciar as divergências estéticas entre o suposto cinema "pós-clássico" e o clássico. Sobre a teorização de Heath em torno aos conceitos de "excesso" e "contenção", no contexto da "dialética do sujeito" elaborada nas páginas da revista britânica Screen em meados dos anos 1970, ver Fernando Mascarello, "A Screen-theory e o Espectador Cinematográfico: Um 80 Panorama Crítico", Novos Olhares 4, 8 ( $2^{\circ}$ semestre de 2001), p. 13-28.

${ }^{14}$ Wyatt, op. cit. Nota 5, p. 31-33.

${ }^{15}$ Thompson, op. cit. Nota 6, p. 139.

${ }^{16}$ Barbara Klinger, "Digressions at the Cinema: Reception and Mass Culture", Cinema Journal 28, 4 (1989), p. 10. Para uma análise em maior profundidade do conceito de intertextualidade contextual proposto neste texto por Klinger, ver Fernando Mascarello, Os Estudos Culturais e a Espectatorialidade Cinematográfica: Uma Abordagem Relativista (Tese de Doutorado - ECA, USP. São Paulo, 2004), p. 88-90. ${ }^{17}$ Wyatt, op. cit. Nota 5, p. 45-46.

${ }^{18} \mathrm{~A}$ análise das trilhas de Batman e Dick Tracy é empreendida por Wyatt às páginas 49-52 de sua obra.

${ }^{19}$ Wyatt, op. cit. Nota 5, p. 60.

${ }^{20}$ Idem, p. 46

\section{Referências}

AUMONT, Jacques; MARIE, Michel. Análisis del Film. 2. ed. Barcelona: Paidós, 1993. Bibliografia: p. 279-281.

BORDWELL, David. Narration in the Fiction Film. Madison, Wisconsin: University of Wisconsin Press, 1985. 
Classical Hollywood Cinema: Narrational Principles and Procedures, in ROSEN, Philip (Org.). Narrative, Apparatus, Ideology. Nova Iorque: Columbia University Press, 1986.

BORDWELL, David; STAIGER, Janet; THOMPSON, Kristin. Classical Hollywood Cinema: Film Style and Mode of Production to 1960. Nova Iorque: Columbia University Press, 1985.

ELSAESSER, Thomas. The Pathos of Failure. American Films in the 1970s: Notes on the Unmotivated Hero. Monogram, n. 6.

HEATH, Stephen. Film and System: Terms of Analysis, Pt. I. Screen, v. 16, n. I, primavera 1975.

KLINGER, Barbara. Digressions at the Cinema: Reception and Mass Culture. Cinema Journal, v. 28, n. 4, verão 1989. Bibliografia: p. 10.

KOLKER, Robert Philip. A Cinema of Loneliness: Penn, Kubrick, Coppola, Scorsese, Altman. Nova Iorque: Oxford University Press, 1980.

KRAMER, Peter. Post-classical Hollywood, in Hill, John; Gibson, Pamela Church (Orgs.). American Cinema and Hollywood. Oxford: Oxford University Press, 2000. Bibliografia: p. 69-79.

MALTBY, Richard. Nobody Knows Everything: Post-classical Historiographies and Consolidated Entertainment, in NEALE, Steve; SMITH, Murray (Orgs.). Contemporary Hollywood Cinema. Londres: Routledge, 1998.

MASCARELLO, Fernando. A Screen-theory e o Espectador Cinematográfico: Um Panorama Crítico. Novos Olhares - Revista de Estudos sobre Práticas de Recepção a Produtos Midiáticos, ano 4, n. 8. 2 semestre de 2001, p. 13-28.

Os Estudos Culturais e a Espectatorialidade Cinematográfica: Uma Abordagem Relativista. Tese de Doutorado - ECA, USP. São Paulo. 2004. Bibliografia: p. 88-90.

NEALE, Steve. New Hollywood Cinema. Screen, v. 17, n. 2.

PYE, Michael; MYLES, Lynda. The Movie Brats: How the Film Generation Took over Hollywood. Nova lorque: Holt, Rinehart \& Winston, 1979.

SCHATZ, Thomas. The New Hollywood, in COLLINS, Jim; RADNER, Hilary; COLLINS, Ava Preacher (Orgs.). Film Theory Goes to the Movies. Nova Iorque: Routledge, 1993. 
SMITH, Murray. Theses on the Philosophy of Hollywood History, in NEALE, Steve (Org.); SMTTH, Murray (Org.). Contemporary Hollywood Cinema. Londres: Routledge, 1998. Bibliografia: p. 11.

THOMPSON, Kristin. The Concept of Cinematic Excess, in ROSEN, Philip (Org.). Narrative, Apparatus, Ideology. Nova Iorque: Columbia University Press, 1986. Bibliografia: p. 132.

WYATT, Justin. High Concept: Movies and Marketing in Hollywood.

Austin: University of Texas Press, 1994. Bibliografia: p. 23-64. 